\title{
Efficacy and tolerability of mirtazapine versus sertraline: an open, randomized study in acute treatment in patients with major depressive disorder
}

\author{
Dahal S1, Ojha SP2 , Chapagain $\mathrm{M}^{3}$,Tulachan $\mathrm{P}^{4}$
}

1. Junior Resident, Department of psychiatry, Maharajgunj Medical Campus, Kathmandu, Nepal 2. Assoc. Prof. Department of psychiatry, Maharajgunj Medical Campus, Kathmandu, Nepal 3. Asst. Prof. Department of psychiatry, Maharajgunj Medical Campus, Kathmandu, Nepal 4. Lecturer, Department of psychiatry, Maharajgunj Medical Campus, Kathmandu, Nepal

Email Corresponding Author: dahalsudina@gmail.com

\begin{abstract}
Introduction: Mirtazapine is the first noradrenergic and specific serotonergic antidepressant (NaSSA). It has demonstrated efficacy that is significantly superior to older and newer anti-depressant in the initial weeks of treatment in western studies. The specific pharmacologic profile of mirtazapine also means that it lacks many of the serotonergic side effects, in particular, sexual dysfunction. The effectiveness of sertraline is well established in major depression.
\end{abstract}

Aim: The aim of the study was to compare the anti-depressant efficacy and tolerability of mirtazapine and sertraline in treatment of patients with a diagnosis of major depressive episode attending Psychiatry department of Tribhuvan University Teaching Hospital.

Methodology: A total of 60 patients meeting the inclusion criteria were selected. These patients were diagnosed as depression as per the ICD-10 DCR criteria and were randomized to 6 week treatment with either mirtazapine ( $N=30,15-45$ $\mathrm{mg} /$ day) or sertraline $(\mathrm{N}=30,50-150 \mathrm{mg} /$ day $)$. Efficacy was evaluated by the HAMD scale, Clinical Global Impression scales (CGI) and UKU side effect rating scale was used for any adverse event noted during study period. Assessments were done on baseline and week 2, 4 and 6 .

Result: The primary efficacy variable (mean absolute change from baseline in HAMD score) showed that mirtazapine was significantly $(p<0.05)$ more effective than sertraline at assessment during 2 and 4 weeks of the study after which there was no statistically significant differences in efficacy $(p>0.05)$ between two drugs. There was statistically significant reduction in CGI- mean severity of illness rating scale score at 2 week $(p<0.05)$ in mirtazapine treated patients compared to sertraline after which reduction of score was similar in both group. Both treatments were well tolerated. Tension (57.6\%), palpitation / tachycardia (26.9\%), sexual dysfunction (22.9\%) were more frequent in sertraline treated patients compared to nausea / vomiting (26.9\%), sleepiness / sedation (23.0\%), increased duration of sleep $(23.0 \%)$ in mirtazapine treated patients.

Conclusion: Mirtazapine was well tolerated and was equally effective as sertraline in reducing depressive symptoms. However, mirtazapine was significantly more effective than sertraline after 2 and 4 week of treatment. The findings need to be confirmed with other large scale studies

Keywords: mirtazapine, sertraline, anti-depressant, major depressive disorder. 


\section{INTRODUCTION}

As most of the anti-depressant require 2 to 4 weeks before the onset of significant symptomatic relief 1 , there always have been quest for newer antidepressant with faster onset of action, better efficacy and with less adverse effects, which enhances adherence to medication thereby decreasing disability and other potentially lifethreatening consequences of depression.

Mirtazapine is the first noradrenergic and specific serotonergic antidepressant (NaSSA), enhancing central noradrenergic and 5HT-1 mediated serotonergic neurotransmission while directly blocking 5HT-2 and 5HT-3 receptors. ${ }^{2}$ It has demonstrated efficacy that is significantly superior to placebo and trazodone, and comparable to that of tricyclic antidepressants. ${ }^{3}$ In comparative studies against the SSRI's fluoxetine ${ }^{4}$, citalopram $^{5}$ and paroxetine ${ }^{6}$, mirtazapine showed statistically significant advantages during the initial weeks of treatment, with differences being observed as early as the first assessment (week 1) in western studies. The specific pharmacologic profile of mirtazapine ${ }^{7,8}$ also means that it lacks many of the serotonergic side effects, in particular, sexual dysfunction. ${ }^{9}$ The effectiveness of sertraline is well established in major depression. The aim of the present study is to compare the anti-depressant efficacy and tolerability of mirtazapine and sertraline, two drugs with different pharmacological profiles, in treatment of patients with ICD-10, DCR diagnosis of major depressive disorder.

\section{MATERIALS AND METHODS:}

This was an open, randomized, comparative and prospective study conducted in patients diagnosed as major depression attending Psychiatry Department of TUTH within a period of six month interval. The sample was selected according to inclusion and exclusion criteria. Those with the clinical history of mental retardation, organic brain syndrome, epilepsy, psychosis, mild depression, severe depression with psychotic symptoms, those with co-morbid substance use except nicotine or other serious medical conditions, those who are pregnant or planning for pregnancy and lactating women were excluded from the study. Informed consent was taken from the patients and their relatives when they were not able to provide consent because of disease severity. A self-designed semi structured proforma was devised to obtain the socio- demographic characteristics of the study population. Also included was a format for the collection of presenting complaints with duration and findings from general physical examination along with mental state examination during presentation.

The diagnosis of depression and its grading as mild, moderate and severe was done on the basis of ICD10, DCR as developed by the division of Mental Health of the World Health Organization (WHO, 1992). It deals with mental and behavioral disorders and the version is mainly used for research purposes. Patients were randomized either to sertraline $(\mathrm{N}=30,50-150 \mathrm{mg} /$ day $)$ or mirtazapine $(\mathrm{N}=30,15-45 \mathrm{mg} /$ day). Efficacy was evaluated by HAMD and Clinical Global Impression at baseline, 2, 4 and 6 week. UKU side effect rating scale was used to assess adverse event noted during study period.

Finally, information obtained from demographic profile and rating scales were analyzed by using suitable statistical tools. Data were analyzed using SPSS version 16 (Chicago, Illinois, USA). The data were explained as mean \pm standard deviation (SD) wherever suitable. Chi- square tests were applied for categorical data. Analysis of rating scale were conducted using Last Observation Carried Forward. Independent sample $\mathrm{t}$ test, ANOVA tests were applied wherever applicable. Most tests were 2 sided and $P_{-}$value of $<0.05$ was considered significant.

\section{RESULTS:}

Out of the total 60 patients, 30 each were randomized to receive mirtazapine $(15-45 \mathrm{mg} /$ day) or sertraline $(50-150 \mathrm{mg} /$ day $)$. Both treatment groups were well matched at baseline with respect to demographic characteristics and rating scales scores.

Four patients in each treatment group drop-out from the study after initial assessment at baseline with subsequent failure to follow up in preceding week.

The mean daily dosages of medication was 87.50 $\mathrm{mg}$ of sertraline and $28.27 \mathrm{mg}$ of mirtazapine.

\section{Efficacy:}

At 2 and 4 week of assessment, the mean reduction in HAMD total score from baseline was significantly $(p<0.05)$ greater with mirtazapine than with sertraline. However at 6 week, mean reduction in HAMD for both group was not statistically significant $(\mathrm{p}>0.05)$ (table 1 , figure 1$)$. 
Table 1: Hamilton rating scale for Depression scores of patients

\begin{tabular}{|l|l|l|l|}
\hline HAMD & $\begin{array}{l}\text { Sertraline } \\
\text { Mean (SD) }\end{array}$ & $\begin{array}{l}\text { Mirtazapine } \\
\text { Mean (SD) }\end{array}$ & p-value \\
\hline $\begin{array}{l}\text { Baseline : } \\
\text { 0 week }\end{array}$ & $23.00(1.98)$ & $21.88(2.50)$ & 0.81 \\
\hline 2 week & $22.23(1.84)$ & $19.27(2.76)$ & $0.00^{*}$ \\
\hline 4 week & $19.77(2.26)$ & $17.19(2.71)$ & $.001^{*}$ \\
\hline 6 week & $12.62(1.72)$ & $12.81(2.757)$ & .764 \\
\hline
\end{tabular}

Table 1 shows the baseline and weekly score of the Hamilton rating scale for depression for both groups of the patients.

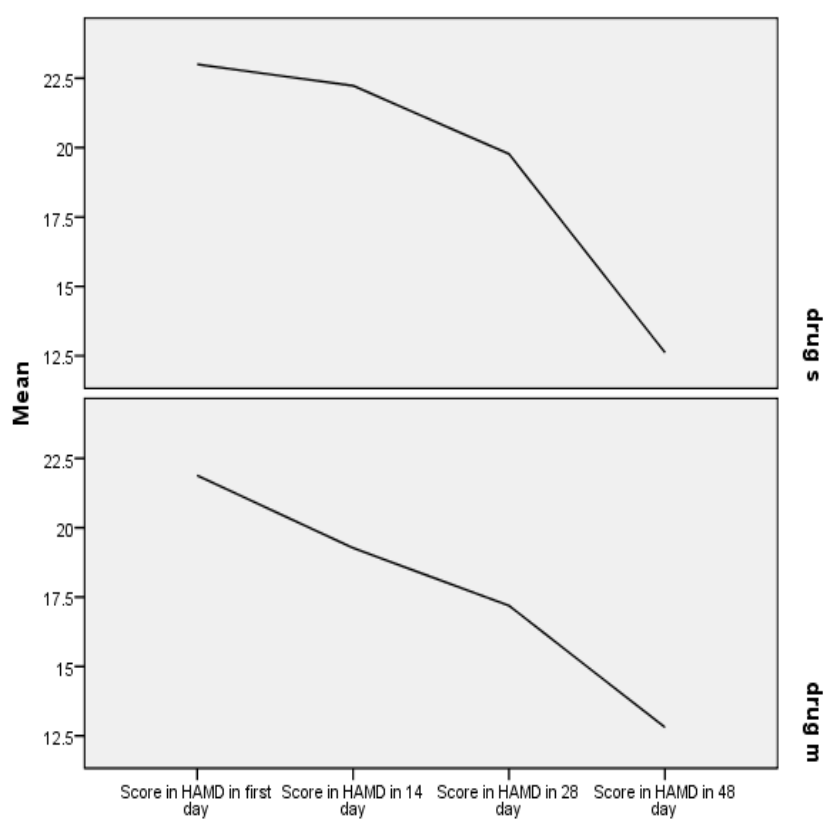

Figure 1: Comparative line diagram showing change in HAMD scores over 6 week study period in both group.

In this study, there was difference in mean severity of illness rating score at 0 and 6 week for both groups, which was statistically significant. The score was significantly reduced at 6 week compared to score at 0 week in both group. However, there was no statistically significant finding between each group of medicines over 6 week of study period ( $p$ $>0.05$ ) except for severity of illness rating score in 2 week $(p<0.05)$ which showed greater reduction in mean severity of illness rating scores in mirtazapine group compared to sertraline group at 2 week (table 2).
Table 2: Mean severity of illness rating scores:

\begin{tabular}{|l|l|l|l|}
\hline Score & $\begin{array}{l}\text { Sertraline } \\
\text { Mean (SD) }\end{array}$ & $\begin{array}{l}\text { Mirtazapine } \\
\text { Mean (SD) }\end{array}$ & p-value \\
\hline 0 week & $4.38(1.134)$ & $4.23(1.032)$ & 0.611 \\
\hline 2 week & $3.85(1.120)$ & $3.19(0.895)$ & $0.024^{*}$ \\
\hline 4 week & $2.96(1.038)$ & $2.50(0.707)$ & 0.067 \\
\hline 6week & $1.35(0.629)$ & $1.19(.402)$ & 0.298 \\
\hline
\end{tabular}

Table 2 shows the mean severity of illness rating score over six week.

There was no statistically significant difference $(p>$ 0.05 ) between Sertraline and Mirtazapine treated group on CGI scores in 2, 4 and 6 week of study period in global improvement and efficacy index rating score (table 3,4 ).

Table 3: Mean global improvement rating scale:

\begin{tabular}{|l|l|l|l|}
\hline Score & $\begin{array}{l}\text { Sertraline } \\
\text { mean (SD) }\end{array}$ & $\begin{array}{l}\text { Mirtazapine } \\
\text { mean (SD) }\end{array}$ & p-value \\
\hline 2 week & $3.35(1.129)$ & $3.19(0.849)$ & 0.581 \\
\hline 4 week & $2.42(0.987)$ & $2.35(0.846)$ & 0.764 \\
\hline 6 week & $1.42(0.578)$ & $1.31(0.471)$ & 0.434 \\
\hline
\end{tabular}

Table 3 shows the mean global improvement rating scale at 2, 4 and 6 week of study period.

Table 4: Mean efficacy index rating score

\begin{tabular}{|l|l|l|l|}
\hline Score & $\begin{array}{l}\text { Sertraline } \\
\text { (SD) }\end{array}$ & $\begin{array}{l}\text { Mirtazapine } \\
\text { (SD) }\end{array}$ & P value \\
\hline 2 week & $8.88(2.026)$ & $9.54(2.319)$ & 0.284 \\
\hline 4 week & $7.88(2.007)$ & $7.77(1.796)$ & 0.828 \\
\hline 6 week & $5.19(1.497)$ & $4.48(1.349)$ & 0.726 \\
\hline
\end{tabular}

Table 4 shows the mean efficacy rating scores over the 6 week.

At the end of the study, $65.38 \%$ of patients in sertraline group and $69.23 \%$ of patients in mirtazapine group showed 'marked improvement (table 5).

Table 5: Percentage of efficacy index rating score on 6 week

\begin{tabular}{|l|l|l|l|}
\hline \multirow{2}{*}{} & \multicolumn{2}{|c|}{ Medicine } & Total \\
\cline { 2 - 4 } & Sertraline & Mirtazapine & \\
\hline \multirow{2}{*}{$\begin{array}{l}\text { Marked } \\
\text { improvement }\end{array}$} & 17 & 18 & 35 \\
\cline { 2 - 4 } $\begin{array}{l}\text { Moderate } \\
\text { improvement }\end{array}$ & $65.38 \%$ & $69.23 \%$ & $67.30 \%$ \\
\cline { 2 - 4 } Total & $34.61 \%$ & 8 & 17 \\
\cline { 2 - 4 } & 26 & $26.7 \%$ & $32.69 \%$ \\
\cline { 2 - 4 } & $100 \%$ & $100 \%$ & $100 \%$ \\
\hline
\end{tabular}

Table 5 shows the number and percentage of patient in efficacy index rating score on 6 week for both groups. 


\section{Safety and Tolerability}

Both treatments were well tolerated. A total of 4 patient in each group of mirtazapine and Sertraline dropped out after the first visit with failure to reattend in further subsequent assessment, drop out probably could be explained by failure to follow-up. The difference in dropouts was not statistically significant. However, at assessment on 2, 4 and 6 weeks there were no dropouts in both group of medicine due to adverse event suggest that, both drugs were well tolerated over a period of 6 week.

The percentage of patients reporting at least 1 adverse event was $73 \%$ with Sertraline and $53.8 \%$ with Mirtazapine treated patients, although the pattern of adverse events was different for both drugs (table 6). , tension (57.6\%), palpitation / tachycardia $(26.9 \%)$, diminished sexual desire ( $15.3 \%)$, nausea / vomiting (11.5\%) were the most common adverse events in sertraline treated group compared to sleepiness/ sedation (23.0\%), increased duration of sleep (23\%), nausea/ vomiting (26.9\%), asthenia/ lassitude / increased fatigability in mirtazapine treated group (table 6).Psychic side effect, mainly the tension component was found more in sertraline treated group when compared with mirtazapine group at 2 and 4 weeks of study period (table 6).

Table 6: Adverse events reported in patients in either treatment group during study period

\begin{tabular}{|c|c|c|c|}
\hline $\begin{array}{l}\text { Adverse } \\
\text { events }\end{array}$ & $\begin{array}{l}\text { Sertraline } \\
(n=26)\end{array}$ & $\begin{array}{l}\text { Mirtazapine } \\
(\mathrm{n}=26)\end{array}$ & $\begin{array}{l}\mathbf{P} \\
\text { value }\end{array}$ \\
\hline $\begin{array}{l}\text { Asthenia/ } \\
\text { lassitude / } \\
\text { increased } \\
\text { Fatiguability }\end{array}$ & & $3(11.5 \%)$ & \\
\hline $\begin{array}{l}\text { Sleepiness/se } \\
\text { dation }\end{array}$ & & $6(23.0 \%)$ & \\
\hline Tension & $15(57.6 \%)$ & & \\
\hline $\begin{array}{l}\text { Increased } \\
\text { duration of } \\
\text { sleep }\end{array}$ & & $6(23.0 \%)$ & \\
\hline Paraesthesia & $1(3.8 \%)$ & & \\
\hline $\begin{array}{l}\text { Nausea/ } \\
\text { vomiting }\end{array}$ & $3(11.5 \%)$ & $7(26.9 \%)$ & $0.038^{*}$ \\
\hline Diarrhoea & $1(3.8 \%)$ & & \\
\hline Constipation & $3(11.5 \%)$ & & \\
\hline $\begin{array}{l}\text { Orthostatic } \\
\text { dizziness }\end{array}$ & & $1(3.8 \%)$ & \\
\hline $\begin{array}{l}\text { Palpitation/ } \\
\text { tachycardia }\end{array}$ & $7(26.9 \%)$ & & \\
\hline $\begin{array}{l}\text { Diminished } \\
\text { sexual desire }\end{array}$ & $4(15.3 \%)$ & $1(3.8 \%)$ & $0.021^{*}$ \\
\hline $\begin{array}{l}\text { Erectile } \\
\text { dysfunction }\end{array}$ & $2(7.6 \%)$ & & \\
\hline
\end{tabular}

Table 6 shows the adverse events reported by patient in either treatment group during the study period of 6 week.

This study showed higher incidence of sexual dysfunction in sertraline group at 6 week. In sertraline group $15.3 \%$ of patients reported diminished sexual desire and $7.6 \%$ erectile dysfunction compared to $3.8 \%$ of patients treated with mirtazapine reported of diminished sexual desire.

\section{DISCUSSION:}

A rapid onset of anti-depressant efficacy is clearly desirable in terms of reduced suffering, reduced risk of suicide, decrease need for hospitalization and improved compliance. There is considerable evidence from previous clinical studies to suggest mirtazapine has a faster onset of effect than the SSRIs. $5,6,7$

In this study, both mirtazapine and sertraline were equally efficacious in alleviating symptoms of depression in patients with major depressive disorder at the end of 6 week. However at week 2 and 4, statistically significant larger magnitude of change from baseline favoring mirtazapine were present in the group mean HAMD score and on CGI-Severity of illness rating scale at 2 week. The present result is in line with other studies. There is considerable evidence from previous clinical studies to suggest that mirtazapine has faster onset of effect than the SSRI's sertraline. ${ }^{10,11,4}$

The mechanisms of action of the SSRIs and mirtazapine are quite distinct and this may explain the difference in the speed of their onset of their therapeutic effects. ${ }^{12}$ Mirtazapine is a dual acting anti-depressant that affects both serotonin and noradrenaline, while the SSRIs have an effect on serotonin only. The SSRI's increase serotonin availability by blocking its reuptake from the synaptic cleft. However, the increased activity in serotonin neurons is attenuated by a- 2 adrenergicreceptor-mediated feedback systems acting on raphe cell bodies and serotonin terminals. With continued treatment, these adrenergic receptors become desensitized and increased availability of serotonin becomes evident. On the other hand, Mirtazapine directly blocks these adrenergic autoreceptors, resulting in a disinhibition of noradrenaline release and increased synaptic availability of serotonin.13,14 The increased availability of serotonin escapes the initial negative feedback system because the a- 2 adrenoreceptors that mediated the feedback are blocked by 
Mirtazapine. The a-2 adrenoreceptors located on the serotonergic cell body are not blocked by Mirtazapine but stimulated by the increased release of noradrenaline. ${ }^{13}$ Activation implies increase in firing rate of the serotonergic system with an increase in synaptic serotonin release. The escape from the negative feedback system and the increase in synaptic serotonin release may be the neurobiological substrate for the faster onset of action of Mirtazapine. ${ }^{10}$

In this study, both treatments were well tolerated. A total of 4 patient in each group of mirtazapine and sertraline dropped out after the first visit with failure to re-attend in further subsequent assessment, drop out probably could be explained by failure to follow-up. However, at assessment on 2, 4 and 6 weeks there were no dropouts in both group of medicine due to adverse event which suggests that both drugs were well tolerated over a period of 6 week.

The percentage of patients reporting at least 1 adverse event was $73 \%$ with Sertraline and $53.8 \%$ with Mirtazapine treated patients, although the pattern of adverse events was different for both drugs. The result was comparable with other similar previous studies. 5,10

When compared with above mentioned studies, the percentage of patient reporting at least one adverse event is quite low in Mirtazapine group.

In this study, tension (57.6\%), palpitation / tachycardia $(26.9 \%)$, diminished sexual desire ( $15.3 \%)$, nausea / vomiting (11.5\%) were the most common adverse events in sertraline treated group compared to sleepiness/ sedation (23 .0\%), increased duration of sleep (23\%), nausea/ vomiting (26.9\%), asthenia/ lassitude / increased fatigability in mirtazapine treated group. Psychic side effect, mainly the tension component was found more in sertraline treated group when compared with mirtazapine group at 2 and 4 weeks of study period. This finding was in line with other study. ${ }^{4}$

The lower percentage of patient in mirtazapine treated group complaining of tension, palpitation, compared to sertraline group in this study could be explained by its mechanism of action. Mirtazapine blockade of 5-HT2 and 5HT-3 receptors may enhance therapeutic effects directly (relief of insomnia, increased appetite) or indirectly by dampening side effects attributable to disinhibited 5 -HT release (agitation or nausea). ${ }^{2}$
Sedation / increased duration of sleep was seen mostly in mirtazapine group (23\%) which was comparable with other similar studies.2,4,10 Mirtazapine is a potent antagonist of histamine 1 receptor which adds to its sedative properties. ${ }^{2}$

The higher incidence of sexual dysfunction was found in sertraline group at 6 week. In sertraline group $15.3 \%$ of patients reported diminished sexual desire and $7.6 \%$ erectile dysfunction compared to $3.8 \%$ of patients treated with Mirtazapine reported of diminished sexual desire. The result is consistent with other similar studies. ${ }^{10}$ These differences in effect on sexual function can be accounted by pharmacological profiles of the two drugs. Thus, while the SSRIs stimulate all post-synaptic serotonin receptors, Mirtazapine selectively blocks 5-HT2 and 5-HT3 receptors, including the 5-HT2A receptor, stimulation of which is associated with sexual dysfunction, anxiety and insomnia in Sertraline treated group ${ }^{7}$

\section{LIMITATIONS:}

We acknowledge that our study consisted of relatively small sample size. Moreover this was a single hospital based study. So, the findings of this study cannot be generalized in the general population.

\section{CONCLUSIONS:}

In conclusion, the results of this study showed that mirtazapine and sertraline were equally effective in reducing symptoms of depression and were well tolerated. However, mirtazapine was significantly more effective than sertraline on 2 and 4 week of therapy.

\section{REFERENCES:}

1. Montgomery SA. Fast-onset anti-depressants.Int Clinical Pharmacology 1997 ;12 (suppl 3 ): S1- S5.

2. De Boer T: The pharmacologic profile of mirtazapine. J Clin Psychiatry. 1996;57[Suppl 4]:19.

3. Holm KJ, Markham A. Mirtazapine. A review of its use in major depression.Drugs.1995; 57: 607-631.

4. Wheatley DP, Van Moffaert M, Timmerman L, Kremer CM. Mirtazapine: efficacy and tolerability in comparison with fluoxetine in patients with moderate to severe major depressive disorder. Mirtazapine-Fluoxetine Study Group. I Clin Psychiatry. 1998 Jun; 59(6):306-12.

5. Leinonen E, Skarstein J, Behnke K, Agren H, Helsdingen JT. Efficacy and tolerability of mirtazapine versus citalopram: a double-blind, randomized study in patients with major depressive disorder. Nordic Antidepressant Study Group. Int Clin Psychopharmacol. 1999 Nov;14(6):329-37. 
6. Benkert O, Szegedi A, Kohnen R. Mirtazapine compared with paroxetine in major depression. J Clin Psychiatry.2000; 61: 656-663.

7. Nutt D: Mirtazapine: Pharmacology in relation to adverse effects. ActaPsychiatr Scand. 1997;391[Suppl]:31-37.

8. Montgomery SA. Safety of mirtazapine: a review. Int Clin Psychopharmacol. 1995; 10 (suppl 4): 37-45.

9. Farah A. lack of sexual adverse effects with mirtazapine. Am J Health Syst Pharm. 1998:55;2195-2196.

10. Behnke, Kirsten, Søgaard, Jesper, Martin, Stephen, Bäuml, Josef, Ravindran, Arun V, Agren, Hans, Vester-Blokland, Estelle D. Mirtazapine Orally Disintegrating Tablet Versus Sertraline: A Prospective Onset of Action Study. Journal of Clinical Psychopharmacology: August 2003 - Volume 23 Issue 4 - pp 358-364.

11. Banerjee et al 2011: Sertraline and Mirtazapine for depression in dementia (HTA-SADD): a randomized, multicenter, double -blind, placebo controlled trial. Lancet 2011;378:403-11.

12. Blier P. pharmacology of rapid-onset anti-depressant strategies. J Clin Psychiatry.2001:62 (suppl 15):12-17

13. Haddjeri $N$, Blier $P$, de Montigny $C$. Noradrenergic modulation of central serotonergic neurotransmission: acute and long term effects of mirtazapine. Int Clin psychopharmacol.1995;10 (suppl 4);11-7.

14. Haddjeri N, Blier P, de Montigny C. Effect of the alpha-2 adrenoreceptor antagonist mirtazapine on the 5hydroxytryptamineystem in the rat brain. J Pharmacol Exp. 1996;227:861-871. 